\title{
Locus of Enterocyte Effacement: A Pathogenicity Island Involved in the Virulence of Enteropathogenic and Enterohemorragic Escherichia coli Subjected to a Complex Network of Gene Regulation
}

\author{
Fernanda M. Franzin ${ }^{1,2}$ and Marcelo P. Sircili \\ ${ }^{1}$ State University of Campinas, Campinas, SP, Brazil \\ ${ }^{2}$ Laboratory of Genetics, Butantan Institute, Vital Brazil Avenue, 05503-000 Sao Paulo, SP, Brazil \\ Correspondence should be addressed to Marcelo P. Sircili; mpalma@butantan.gov.br
}

Received 5 September 2014; Accepted 3 November 2014

Academic Editor: Alfredo Torres

Copyright (C) 2015 F. M. Franzin and M. P. Sircili. This is an open access article distributed under the Creative Commons Attribution License, which permits unrestricted use, distribution, and reproduction in any medium, provided the original work is properly cited.

\begin{abstract}
The locus of enterocyte effacement (LEE) is a $35.6 \mathrm{~kb}$ pathogenicity island inserted in the genome of some bacteria such as enteropathogenic Escherichia coli, enterohemorrhagic E.coli, Citrobacter rodentium, and Escherichia albertii. LEE comprises the genes responsible for causing attaching and effacing lesions, a characteristic lesion that involves intimate adherence of bacteria to enterocytes, a signaling cascade leading to brush border and microvilli destruction, and loss of ions, causing severe diarrhea. It is composed of 41 open reading frames and five major operons encoding a type three system apparatus, secreted proteins, an adhesin, called intimin, and its receptor called translocated intimin receptor (Tir). LEE is subjected to various levels of regulation, including transcriptional and posttranscriptional regulators located both inside and outside of the pathogenicity island. Several molecules were described being related to feedback inhibition, transcriptional activation, and transcriptional repression. These molecules are involved in a complex network of regulation, including mechanisms such as quorum sensing and temporal control of LEE genes transcription and translation. In this mini review we have detailed the complex network that regulates transcription and expression of genes involved in this kind of lesion.
\end{abstract}

\section{Introduction}

Attaching and effacing (A/E) is a histological lesion that occurs in intestinal epithelial cells as consequence of infection by a group of pathogens that includes enteropathogenic Escherichia coli (EPEC), enterohemorrhagic Escherichia coli (EHEC), rabbit diarrheagenic Escherichia coli (RDEC), the murine pathogen Citrobacter rodentium, and Escherichia albertii [1]. The A/E lesion was first described by Moon et al. 1983 [2] and is characterized by intimate attachment of bacteria to the enterocyte membrane, destruction of the brush border microvilli, and striking cytoskeletal changes that include accumulation of polymerized actin beneath the site of attachment, forming pedestal-like structures [3-6]. The intimate attachment of $\mathrm{A} / \mathrm{E}$ pathogens to enterocyte surface is mediated through interactions of the bacterial outer membrane protein intimin and the translocated intimin receptor (Tir) [7]. Tir and other effector proteins are delivered to the host cell via a type III secretion system (T3SS).

The genes responsible for $\mathrm{A} / \mathrm{E}$ lesion phenotype are encoded on a $35.6 \mathrm{~Kb}$ pathogenicity island known as locus of enterocyte effacement (LEE) $[2,6,8,9]$, which comprises the structural components of type III secretion system (TTSS), regulators, chaperones, and effectors secreted by the TTSS. LEE was first described in EPEC E2348/69 by Mcdaniel et al. 1995 [10] and consists of 41 ORFs functionally organized into five operons called LEE1, LEE2, LEE3, LEE4, and LEE5 [11]. $L E E 1, L E E 2$, and $L E E 3$ harbors the esc and sep genes, encoding the major components of type III secretion system [12]. LEE1 harbors the LEE encoded regulator (ler) gene, which encodes Ler, a DNA binding protein which acts as a main transcriptional regulator of the LEE region, modulating the 
expression of other LEE operons [13]. The LEE5 operon contains the EPEC attaching and effacing (eae) and translocated intimin receptor (tir) genes, which encodes the adhesion intimin and its receptor Tir, respectively. The effector proteins translocated via type III secretion system to the host cell are encoded by espAesp $B, \operatorname{esp} D$, sepL, espF, and escF genes, located at LEE4 operon $[9,14,15]$.

Enteropathogenic Escherichia coli (EPEC) are among the most important pathogens causing persistent diarrhea in children and adults worldwide $[6,16-18]$. Outbreaks of EPEC were frequent in developed countries in the 1940s and 1950s [19] but have largely disappeared from industrialized countries. However, EPEC continues to be an important cause of child mortality in developing countries. In Brazil and other developing countries, EPEC is associated with at least $20 \%$ of the cases of diarrhea [18, 20-22]. EPEC have been divided into two subgroups: typical EPEC (tEPEC) and atypical EPEC (aEPEC), based on the presence or absence of the EPEC adherence factor plasmid (pEAF), respectively $[6,23]$. Atypical EPEC has been shown to be more prevalent than typical EPEC in developed and developing countries and is considered an emergent cause of endemic diarrhea in children and diarrhea outbreaks in adults [3-5].

Enterohemorrhagic Escherichia coli (EHEC) are a leading cause of bloody diarrhea and hemolytic uremic syndrome (HUS) throughout the world [24]. EHEC strains of the O157:H7 serotype are the most important EHEC pathogens in North America, the United Kingdom, and Japan [6]. This strain has been associated with numerous outbreaks worldwide and constitutes a serious public health threat. EHEC produces a potent Shiga toxin (Stx) that is responsible for the major symptoms of hemorrhagic colitis and HUS [25].

Although their sites of infection are different, EPEC infects the small bowel and EHEC colonizes the large bowel, these two E. coli pathotypes share a similar mode of infection, since both are A/E pathogens [6]. EPEC and EHEC must control virulence gene expression during infection aiming for maximal energy efficiency. Regulation of LEE gene expression is a highly complex and coordinated process, dependent on environmental conditions, quorum sensing, and several regulators and regulatory pathways, in a direct or indirect way.

This review is focused on summarizing the current knowledge of regulation of LEE gene expression in EPEC and EHEC and the molecules involved in this regulation are listed in Table 1.

\section{LEE-Encoded Regulators}

The central regulator which controls the expression of LEE genes is Ler, a $15 \mathrm{kDa}$ protein encoded by the first gene of the LEE1 operon, which is a HNS-like regulatory protein $[11,13,26-29]$. Ler is essential for the formation of A/E lesions, since nonpolar ler mutants of EPEC and EHEC were unable to form A/E lesions on HEp-2 cells [13]. In addition, these ler mutants failed to express type III secreted proteins, which means that all genes known to be important in $\mathrm{A} / \mathrm{E}$ lesion formation are regulated by Ler [13]. Since Ler expression is central to regulation of virulence genes, it is true that the regulation of Ler expression is important to pathogenesis. In fact, Ler expression is under control of numerous regulatory factors, encoded in or out of the LEE region.

Global regulator of LEE activator (GrlA) and global regulator of LEE repressor (GlrR), two other LEE-encoded regulators, were described by Deng et al. 2004 [30] in a $C$. rodentium background. These regulators are encoded by the grlRA operon located between the rorf3 gene and the LEE2 operon in LEE. GrlA has been shown to play a key role in the regulation of ler and thus in the expression of LEE genes. The observation that transcription of LEE1, LEE2, and LEE5 was diminished in $g r l A$ mutants and the transcription of LEE1 was mildly elevated in $g r l R$ mutants has suggested the activator and repressor roles of LEE gene transcription to GrlA and GrlR, respectively. GrlA has been shown to bind on LEE1 promoter and positively regulate Ler expression. Ler also controls the expression of the $g r l R A$ operon, forming a positive regulatory loop that ensures the appropriate level of Ler to activate LEE gene expression [31]. Using a yeast two-hybrid system, it was reported that GrlR specific binds to GrlA [32]. This interaction represses LEE gene expression by preventing GrlA interaction with LEE1 promoter [33] or rather prevents repression by GrlR, which inhibits LEE gene transcription specifically and independently of its interaction with GrlA [34].

\section{Non-LEE-Encoded Regulators}

As the LEE is an essential virulence determinant of pathogenesis of EPEC and EHEC, the expression of its genes is under control of a myriad of transcriptional regulators.

In typical EPEC, the LEE genes are regulated by a region located on a $90 \mathrm{~kb}$ EPEC adherence factor plasmid (EAF plasmid) called plasmid encoded regulator (Per). The per locus includes per $A$, per $B$, and perC transcribed as a single polycistronic message [35]. Mellies et al. (1999) demonstrated that Per indirectly activates LEE2 and LEE3 in this pathogen. PerC directly activates $L E E 1$ promoter and then Ler acts on LEE2, LEE3, LEE4, and LEE5 promoters. Bustamante et al. (2001) have shown that perC gene is indirectly required for LEE2 and LEE3 transcription. PerC have been reported to induce ler transcription independently of GrlA [36]. In EHEC, a family of functional prophage-encoded PerC homologous proteins, called PchA, PchB, and PchC, plays an important role in ler expression [37]. Moreover, a PerC-like protein family identified from EHEC genome analyses, PerC1 (also termed PchABC), can also activate both promoters in a manner similar to that of EPEC PerC. PerC1 proteins are able to mediate activation of the EPEC and EHEC LEE1 promoters in a PerC-like manner, while PerC2 (and PerC3) seems to be inactive. This finding correlates with the fact that PerCl is more closely related to PerC than is PerC2, and much more so than PerC3 [38].

$\mathrm{H}-\mathrm{NS}$ is a $15.6 \mathrm{kDa}$ nucleoid-associated protein that binds nonspecifically to DNA and modulates, mostly negatively, the expression of genes involved in many different cellular processes, including virulence [34]. H-NS plays an important role in the repression of LEE genes $[13,28,30]$. It binds to EPEC LEE1, LEE2, LEE3, and LEE5 regulatory regions, 
TABLE 1: Regulators involved in LEE genes transcription.

\begin{tabular}{|c|c|c|c|c|}
\hline Regulator & Bacteria & Regulatory mechanism & Phenotype/response & References \\
\hline \multicolumn{5}{|l|}{ LEE-encoded } \\
\hline GrlA & $\begin{array}{l}\text { C. rodentium; } \\
\text { EPEC, EHEC }\end{array}$ & Binding $L E E 1$ promoter & $\begin{array}{l}\text { Activates LEE expression } \\
\text { through Ler }\end{array}$ & Deng et al., 2004 [30] \\
\hline GrlR & $\begin{array}{l}\text { C. rodentium; } \\
\text { EPEC, EHEC }\end{array}$ & $\begin{array}{l}\text { Binding to GrlA preventing } \\
\text { it to bind } L E E-1 \text { promoter }\end{array}$ & $\begin{array}{l}\text { Represses Ler/LEE } \\
\text { expression }\end{array}$ & Deng et al., 2004 [30] \\
\hline Ler & A/E pathogens & Binding to LEE promoters & $\begin{array}{l}\text { Activates expression of all } \\
\text { LEE operons }\end{array}$ & Elliott et al., 2000 [13] \\
\hline \multicolumn{5}{|l|}{ Non-LEE encoded } \\
\hline BipA & EPEC, EHEC & Activates ler transcription & $\begin{array}{l}\text { Activates LEE expression } \\
\text { through Ler }\end{array}$ & Grant et al., 2003 [46] \\
\hline Cpx & EPEC, EHEC & $\begin{array}{l}\text { Downregulates } L E E 4 \text { and } \\
\text { LEE-5 transcription }\end{array}$ & Represses LEE expression & Macritchie et al., 2008 [51] \\
\hline Fis & EPEC & $\begin{array}{l}\text { Activates ler and LEE4 } \\
\text { transcription }\end{array}$ & Activates LEE expression & Goldberg et al., 2001 [45] \\
\hline GadE & EHEC & & Represses LEE expression & Vanaja et al., 2009 [50] \\
\hline Hha & EHEC & Binding ler promoter & Represses Ler transcription & Sharma and Zuerner, 2004 [48] \\
\hline H-NS & EPEC, EHEC & $\begin{array}{l}\text { Binding to } L E E 1, L E E 2 \text {, } \\
L E E 3 \text { and } L E E 5 \text { regulatory } \\
\text { region }\end{array}$ & Represses Ler expression & Bustamante et al., 2001 [28] \\
\hline IHF & EPEC & $\begin{array}{l}\text { Binding upstream to ler } \\
\text { promoter }\end{array}$ & $\begin{array}{l}\text { Activates ler, orf3, orf5, and } \\
\text { orf } 2 \text { expression }\end{array}$ & Friedberg et al., 1999 [26] \\
\hline Pch/PerC $1,2^{*}, 3^{*}$ & EHEC & Enhancing ler transcription & $\begin{array}{l}\text { Activates LEE expression } \\
{ }^{*} \text { represses LEE1 } \\
\text { transcription }\end{array}$ & $\begin{array}{l}\text { Iyoda and Watanabe, 2004, [44] } \\
\text { Porter et al., } 2005 \text { [38] }\end{array}$ \\
\hline PerC & Typical EPEC & Activating LEE1 promoter & Activates LEE expression & Mellies et al., 1999 [11] \\
\hline $\operatorname{RgdR}$ & EHEC & $\begin{array}{l}\text { Activating } L E E 1 \\
\text { transcription }\end{array}$ & Activates LEE expression & Flockhart et al., 2012 [47] \\
\hline RpoN & EHEC & $\begin{array}{l}\text { Activating } g r l A, \text { repressing } \\
\text { gadE }\end{array}$ & Activates LEE expression & Riordan et al., 2010 [49] \\
\hline SspA & EHEC & $\begin{array}{l}\text { Repressing H-NS } \\
\text { expression }\end{array}$ & Activates LEE expression & Goldberg et al., 2001 [45] \\
\hline FusK/R & EHEC & Represses LEE1 & Represses LEE expression & Pacheco et al., 2012 [68] \\
\hline EutR & EHEC & Activates $L E E 1$ & Activates LEE expression & Kendall et al., 2012 [69] \\
\hline LeuO & EHEC & Activates $L E E 1$ & Activates LEE expression & Takao et al., 2014 [67] \\
\hline SdiA & EHEC & represses $L E E 1$ & represses LEE expression & Sheng et al., 2013 [74] \\
\hline \multicolumn{5}{|l|}{ Posttranscriptional } \\
\hline ClpXP & EHEC & $\begin{array}{l}\text { Regulating intracellular } \\
\text { protein levels of GrlR and } \\
\text { RpoS }\end{array}$ & $\begin{array}{l}\text { Positively regulates LEE } \\
\text { expression }\end{array}$ & $\begin{array}{l}\text { Tomoyasu et al., } 2005 \text { [56]; } \\
\text { Iyoda and Watanabe, } 2005 \text { [37] }\end{array}$ \\
\hline CsrA & EPEC & $\begin{array}{l}\text { Binding to the leader } \\
\text { segment of the } \\
\text { sepL espADB mRNA and } \\
\text { enhancing the steady-state } \\
\text { transcript and protein levels }\end{array}$ & $\begin{array}{l}\text { Positively regulates LEE } \\
\text { expression }\end{array}$ & Bhatt et al., 2009 [55] \\
\hline $\operatorname{DegP}$ & EPEC & $\begin{array}{l}\text { Protease and chaperone } \\
\text { activity }\end{array}$ & Represses LEE expression & Macritchie et al., 2012 [52] \\
\hline DsrA & EHEC & $\begin{array}{l}\text { Affecting the levels of } \\
\text { functional transcripts of ler }\end{array}$ & Activates LEE expression & Laaberki et al., 2006 [58] \\
\hline $\mathrm{Hfq}$ & EHEC & $\begin{array}{l}\text { Acting in ler and } g r l R A \\
\text { mRNA }\end{array}$ & $\begin{array}{l}\text { Activates or represses LEE } \\
\text { expression, depending on } \\
\text { the strain background }\end{array}$ & $\begin{array}{l}\text { Shakhnovich et al., } 2009 \text { [63]; } \\
\text { Hansen and Kaper, } 2009 \text { [64]; } \\
\text { Kendall et al., } 2011 \text { [65] }\end{array}$ \\
\hline
\end{tabular}


TABLe 1: Continued.

\begin{tabular}{|c|c|c|c|c|}
\hline Regulator & Bacteria & Regulatory mechanism & Phenotype/response & References \\
\hline RNaseE & EHEC & $\begin{array}{l}\text { Splicing at the C-terminal } \\
\text { end of sepL in the precursor } \\
\text { sepL espADB transcript }\end{array}$ & $\begin{array}{l}\text { Generates the sepL and } \\
\text { espADB transcripts }\end{array}$ & Lodato and Kaper, 2009 [53] \\
\hline RpoS & EHEC & Binding to ler promoter & $\begin{array}{l}\text { Activates or represses LEE } \\
\text { expression, depending on } \\
\text { the strain background }\end{array}$ & $\begin{array}{l}\text { Sperandio et al., } 1999 \text { [57]; } \\
\text { Laaberki et al., } 2006 \text { [58]; } \\
\text { Tomoyasu et al., } 2005 \text { [56]; } \\
\text { Iyoda and Watanabe, } 2005 \text { [37] }\end{array}$ \\
\hline \multicolumn{5}{|c|}{ Quorum sensing } \\
\hline KdpE & EHEC & Binding to ler promoter & Activates LEE expression & Njoroge et al., 2013 [70] \\
\hline QseA & EPEC, EHEC & Binding to ler promoter & Activates LEE transcription & $\begin{array}{l}\text { Sperandio et al., } 2002 \text { [80]; } \\
\text { Sircili et al., 2004 [71] }\end{array}$ \\
\hline QseC & EHEC & $\begin{array}{l}\text { Phosphorylation of KdpE } \\
\text { RR }\end{array}$ & Activates LEE expression & Sperandio et al., 2002 [80] \\
\hline QseD & EHEC & Binding to ler promoter & Represses LEE transcription & Habdas et al., 2010 [83] \\
\hline QseE & EHEC & $\begin{array}{l}\text { Inhibiting RcsB RR } \\
\text { transcription }\end{array}$ & Represses LEE expression & $\begin{array}{l}\text { Reading et al., } 2007 \text { [81]; } \\
\text { Njoroge et al., } 2013 \text { [70] }\end{array}$ \\
\hline RcsB & $\begin{array}{l}\text { EHEC O157:H7; } \\
\text { EHEC Sakai }\end{array}$ & & Activates LEE transcription & Njoroge et al., 2013 [70] \\
\hline GlmY/GLMz & EHEC & & $\begin{array}{l}\text { Regulates transcription of } \\
\text { LEE4 and LEE5 }\end{array}$ & $\begin{array}{l}\text { Gruber and Sperandio, } 2014 \\
\text { [66] }\end{array}$ \\
\hline
\end{tabular}

directly controlling LEE transcription [29, 39]. It has been shown that different transcriptional regulators can counteract the repression mediated by $\mathrm{H}$-NS on the expression of virulence genes [40-42]. Ler can neutralize the silencing exerted by $\mathrm{H}-\mathrm{NS}$ on LEE promoters $[28,30,36]$ but not on its own promoter that is also repressed by H-NS [30]. Ler binds with higher affinity than H-NS to the same region of LEE5 and LEE2, disrupting H-NS-containing nucleoprotein complexes [27, 28, 43]. The E. coli stringent starvation protein A (SspA) is involved in downregulation of the cellular H-NS level during stationary phase $[36,44]$. It also has a role in positive regulation of virulence genes in EHEC, since it was demonstrated that in the absence of SSpA, EHEC produces high levels of H-NS which represses the expression of LEE genes, rendering cells incapable of forming A/E lesions [45].

Friedberg et al. (1999) demonstrated that integration host factor (IHF) is essential for expression of LEE-encoded type III secretion genes and directly activates LEE1 transcriptional unit. IHF acts by disrupting the Ler repression by HNS binding specifically upstream from the ler promoter to activate expression of ler, orf3, orf5, and orf2 directly [26]. The overcoming of $\mathrm{H}$-NS silencing of the ler promoter requires the combined antirepressor activity of IHF with PerC or GrlA [34].

Another nucleoid-associated protein that has an impact upon virulence gene expression in EPEC is the factor for inversion stimulation (Fis). Fis was reported to positively regulate ler and LEE4 expression. Goldberg et al. (2001) [45] have shown that major EPEC secreted proteins (EspA, $\mathrm{EspB}$, and $\mathrm{EspD}$ ) were found to be significantly reduced and that ler expression was abolished in the $\Delta$ fis mutant, resulting in inability to induce A/E lesion. However, tir and intimin expressions were found to be unaffected in these mutants, which suggest that the promoter of this operon is not regulated by Fis.

In EPEC, the ribosome-binding GTPase BipA has been shown to modulate virulence expression by increasing LEE transcription, since several key proteins encoded by LEE had lower levels in the absence of BipA. Transcription of ler was reduced in the absence of BipA, suggesting that this GTPase acts most likely indirectly through activating expression of Ler [46].

Recently, Flockhart et al. (2012) [47] have reported a new LEE regulator, termed $\mathrm{RgdR}$, that is encoded in CP933 prophage of O157:H7 and activates LEE1 transcription in the presence or absence of Ler. Sharma and Zuerner (2004) [48] have reported that EHEC O157:H7 mutants of hha gene showed 10-fold increase of ler transcription, suggesting that Hha acts as a repressor of ler transcription by binding to its promoter.

Alternative sigma factor $54(\mathrm{RpoN})$ is one of seven RNA polymerase sigma subunits in E. coli required for promoterinitiated transcription. RpoN was shown to positively regulate the expression of genes in all five LEE operons [49], perhaps through indirect activation of grlA. RpoN may also regulate LEE through GadE, since gadE expression was upregulated in $\triangle r p o N$ mutant [48]. GadE is a transcriptional activator of the glutamate decarboxylase (GAD) system of $E$. coli and has been reported to repress LEE expression in a ler dependent fashion [50].

The Cpx two-component system regulates an envelope stress response adapted by Escherichia coli to monitor and maintain cell envelope integrity. This pathway also has a direct effect on transcription of virulence genes and virulence regulators in different pathogens. Activation of the Cpx pathway negatively affects EPEC TTSS by downregulating the 
expression of components of the translocation apparatus as well as the receptor Tir [51]. Cpx pathway is capable of inhibiting LEE expression in a nonpathogenic E. coli background, which suggests that Cpx-mediated inhibition of LEE gene expression and TTSS is independent of Ler. Cpx response might also inhibit T3SS in EPEC at posttranscriptional levels and DegP is a contributing factor in this inhibition [52].

Whereas our knowledge about the mechanisms of transcriptional regulation of the LEE is vast, our understanding of posttranscriptional and posttranslational regulation is limited. In term of posttranscriptional and posttranslational regulation, RNase E generates the sepL and espADB transcripts by splicing at the C-terminal end of sepL in the precursor sepLespADB transcript of EHEC [53]. CsrA, an RNA-binding protein [54], is a posttranscriptional regulator molecule in A/E pathogens that activates and represses the expression of LEE-encoded genes in a concentration-dependent manner [55]. CsrA exerts its effect by binding to the leader segment of the sepLespADB mRNA and enhancing the steady-state transcript and protein levels.

ClpX and ClpP were suggested to be positive regulatory genes that control expression of LEE in EHEC O157. It was shown that O157:H7 Sakai clpPX mutant strongly impaired the secretion of virulence proteins by TTSS and repressed transcription from all the LEE promoters. This positive regulation partially depends on the intracellular levels of RpoS, a substrate for the ClpXP protease, since the $\Delta r p o S$ mutation in O157:H7 Sakai enhanced the transcription from all the LEE promoters and the secretion of virulence proteins, and it could partially suppress the defects of the $\triangle c l p P X$ mutation. However, the regulation of LEE by ClpXP also occurs in a sigma-(S-) independent pathway that involves the negative regulation of GrlR levels in $\operatorname{EHEC~}[37,56]$.

The stress sigma factor RpoS has also been involved in regulatory cascades controlling LEE expression [37, 57]. The effects of RpoS on expression of the LEE virulence genes appear to vary depending on strain backgrounds and experimental conditions. Laaberki et al. (2006) [58] have reported that the $L E E 3$ operon and tir are positively regulated by RpoS in EHEC strain 86-24. However, in EHEC O157:H7 Sakai strain, LEE expression is enhanced in rpoS mutants $[37,56,58]$ due to increases in ler mRNAs levels [58], indicating that RpoS could repress ler expression. RpoS acts by binding to ler promoter to activate the transcription through a pathway different than that used by H-NS. In turn, RpoS translation depends on the high levels of DsrA, a noncoding RNA (ncRNA) which modulates the expression of RpoS and H-NS.

Noncoding RNAs (ncRNAs) have recently emerged as important regulators involved in controlling the expression of regulatory and effector genes [59]. DsrA acts by an antisense base-pairing mechanism on $\mathrm{H}-\mathrm{NS}$ mRNA, decreasing its stability, and on RpoS mRNA, stimulating its translation $[60,61]$. DsrA enhances ler expression by affecting the levels of functional transcripts and the DsrA-mediated activation of LEE requires Ler. DsrA effects on the expression of intimin and EspA would mainly be due to its effect on ler expression and the DsrA activation of ler expression requires RpoS [58].
DsrA also affects the H-NS levels; however RpoS- and HNSdependent pathways separately regulate ler expression.

$\mathrm{Hfq}$ is a conserved RNA-binding protein that regulates diverse cellular processes through posttranscriptional control of gene expression, often by functioning as a chaperone for regulatory sRNAs in many bacterial species [62]. Hfq has been described as a negative regulator of the expression of all of the 41 LEE genes acting directly upon ler mRNA, as translation of this transcript is increased in the absence of Hfq in EHEC EDL933 [63]. Hansen and Kaper (2009) have shown that Hfq negatively affects LEE expression in exponential phase by regulating the expression of the LEEencoded regulators GrlA and GrlR at the posttranscriptional level by destabilizing $g r l R A$ mRNA. Hfq negatively affects LEE expression in stationary phase independent of GrlA and GrlR in EHEC EDL933 [64]. However, Kendall et al. (2011) have reported that Hfq plays a regulatory role in EHEC 8624 that is different from what has been reported for EHEC strain EDL933, acting as a positive regulator of the TTSS expression and A/E lesion formation in this strain [65]. Taken together, these studies point to the possibility that this kind of regulation might be different even in closely related strains.

Recently, Gruber and Sperandio noticed that LEE and espFu genes are posttranscriptionally regulated by the GlmY/GlmZ sRNAs. GlmY and GlmZ promote cleavage of the intergenic region between espJ and espFu to allow the translation of EspFu [66].

\section{Environmental Signals Such as Carbon Sources}

There are recent studies correlating some carbon sources to LEE regulation. Takao et al. 2014 noticed that LeuO can recognize butyrate and activate a signaling cascade. LeuO expression induces prolonged activation of the promoter of LEE1 operon, including the ler gene, as well as virulence mechanisms such as microcolony formation. Activation of the LEE1 promoter by LeuO depends on another regulator, called Pch. The response of the leuO promoter to butyrate requires two virulence regulators, Pch and Ler, in addition to Lrp. Pch, Ler, and Lrp bind the upstream region of the leuO promoter. Thus, leuO is involved in butyrate-enhanced expression of LEE genes through a positive feedback mechanism, but its expression and action on the LEE1 promoter are dependent on the virulence regulators Pch and Ler [67].

Another sugar that is highly abundant in the intestine is fucose. Recently, Pacheco et al. described a mechanism of fucose recognition and virulence regulation. They described one novel two-component signal transduction system, named FusKR, where FusK is the histidine sensor kinase and FusR the response regulator. FusK senses fucose and controls expression of virulence and metabolic genes. This fucose-sensing system is required for robust EHEC colonization of the mammalian intestine [68]. Ethanolamine can act as a signal to modulate virulence. The EutR transcription factor, known to be the receptor of EA, is only partially responsible for this regulation, suggesting that yet another EA receptor exists. Ethanolamine (EA) is present in the large intestine due to the turnover of intestinal cells. Kendall et 
al. 2012 showed that during growth at early log phase, ler expression in WT EHEC was increased over 10-fold when EA was added to the medium. At mid- and late log phases, the addition of EA did not significantly affect the level of ler transcription [69]. Njoroge et al., 2013 studied the role of Cra and KdpE and concluded that although these regulators clearly have individual targets, they also share either convergent or divergent regulation of subsets of genes. Cra positively regulate the genes encoding gluconeogenic enzymes, and negatively regulate genes encoding glycolytic enzymes. Cra and KdpE converge in the regulation of the LEE T3SS and several non-LEE-encoded effectors, which agrees with the fact that the expression of these genes should be coupled, even though they are found in different chromosomal regions. Both transcription factors activate LEE1 expression under gluconeogenic conditions. Another factor involved in the trigger of AE lesion is the phosphorylation of Tir and the accessory protein EspFu/Tccp [70].

\section{Quorum Sensing and Signaling Systems}

Several signaling systems have been well studied between host-cell pathogens interactions; among them there are at least four involved in chemical signaling described in the literature: (1) AI-1 System, (2) AI-2 System, (3) AI3/epinephrine system, and (4) indole. At least two systems were described in mechanisms involved in LEE gene regulation in EPEC and EHEC strains.

The first study reporting quorum sensing regulation of LEE in EHEC and EPEC was performed by Sperandio et al. (1999). In this pioneering study, they noticed that the transcription of $L E E 1$ and $L E E 2$ was increased in the presence of preconditioning media, suggesting that EPEC and EHEC secrete AI-2 [57]. At that time point it was proposed that AI-2 acts by activating these operons and thus positively regulating the expression of TTSS genes. Another study performed by Sircili et al. 2004 using one E2348/69 EPEC strain noticed that qse $A$ and $l u x S$ were involved in LEE genes transcription altering TTSS expression and reducing A/E lesion formation [71]. Later studies noticed that AI-2 was not involved in this mechanism of regulation, and the molecule involved was actually AI-3.

\section{AI-1 System and Indole}

Escherichia coli does not harbor one luxI homologue and does not produce the autoinducer, although it harbors one luxR homologue which is called $s d i A$. SdiA is responsible for sensing the environmental AI-1 signals produced by other microorganisms [72]. Studies with SdiA mutants have shown that this regulator may be involved in biofilm formation in E. coli. SdiA has been proposed to interact with indole [73], in addition to acyl homoserine lactones (AHLs) from other bacteria. However, conclusive data demonstrating that SdiA senses that indole is lacking. In E. coli, SdiA, named after its ability to suppress cell division inhibitors, is a 240 -aminoacid protein that belongs to the LuxR family of transcriptional regulators. Sheng et al. 2013 noticed that deletion of sdiA removes the ability to sense AHLs and regulate LEE and gad gene expression, and as a result the sdiA mutant did not grow well in rumen and was defective, compared to the WT, for colonization of the RAJ mucosa of these cattle. They report that these animals, still harbor AHLs in their rumen, and these AHLs can still repress ler and increase gad gene expression in an SdiA-dependent way [74]. One recent work of Bommarius et al., showed that indole derivatives also represses production of LEE virulence factors and inhibit pedestal formation on mammalian cells [75].

\section{AI-3/Epinephrine/Norepinephrine System}

AI-3/epinephrine/norepinephrine system was first described in enterohemorrhagic E. coli O157:H7 (EHEC) strains [76]. It was initially thought that the gene responsible for production of the molecule was $\operatorname{luxS}$, since $\operatorname{luxS}$ mutant has diminished AI-3 production. Another study performed by Sperandio's group showed that luxS mutants have metabolic deficiencies, and $\operatorname{lu} x S$ is not responsible for AI-3 production [77]. The AI-3 signal is an aromatic compound, and the host hormones epinephrine and norepinephrine can restore AI-3-dependent phenotypes in EHEC. Based on that, it has been proposed that this system is involved in host cell-bacteria communication, and interkingdom signaling. The AI-3 receptor, QseC sensor kinase [78] has been extensively described in EHEC and other species. Subsequent studies showed that AI3/epinephrine/norepinephrine system is not restricted to $E$. coli strains [79].

EHEC and EPEC luxS mutant both present diminished AI-3 production and do not express the LEE-encoded T3SS system at normal levels, nonetheless still form AE lesions on epithelial cells that were indistinguishable from those seen with wild type. luxS mutants were still responding to eukaryotic cell signals to activate expression of the LEE genes. These signals were identified as the hormones epinephrine and norepinephrine. Epinephrine and norepinephrine can substitute for AI-3 to activate transcription of the LEE genes, type III secretion, and AE lesions on epithelial cells.

In EHEC, the mammalian hormones epinephrine and norepinephrine, which are released by the host during stress, are sensed by the QseC receptor to regulate bacterial virulence genes $[80,81]$. The $q s e C$ mutant is attenuated for virulence, which underscores the importance of this interkingdom communication to the development of disease [78]. Regarding atypical EPEC, we performed studies using one qseC mutant and noticed a similar pattern of regulation (unpublished results).

Concerning the EHEC AI-3/epinephrine/norepinephrine signaling system cascade, there are other transcriptional regulators involved; however the timing and interactions still need more studies to be elucidated. We can cite some of these molecules, such as QS E. coli regulator (QseA) [80]. QseA is transcriptionally activated through QS and, in turn, binds to and directly activates transcription of the LEEencoded regulator Ler. Interestingly, qseA mutant in EPEC has a similar reduction in TTSS, but has defect in motility [71], suggesting a different kind of regulation between these two pathotypes, at least regarding these two strains tested. Another two-component system, named QseBC is 


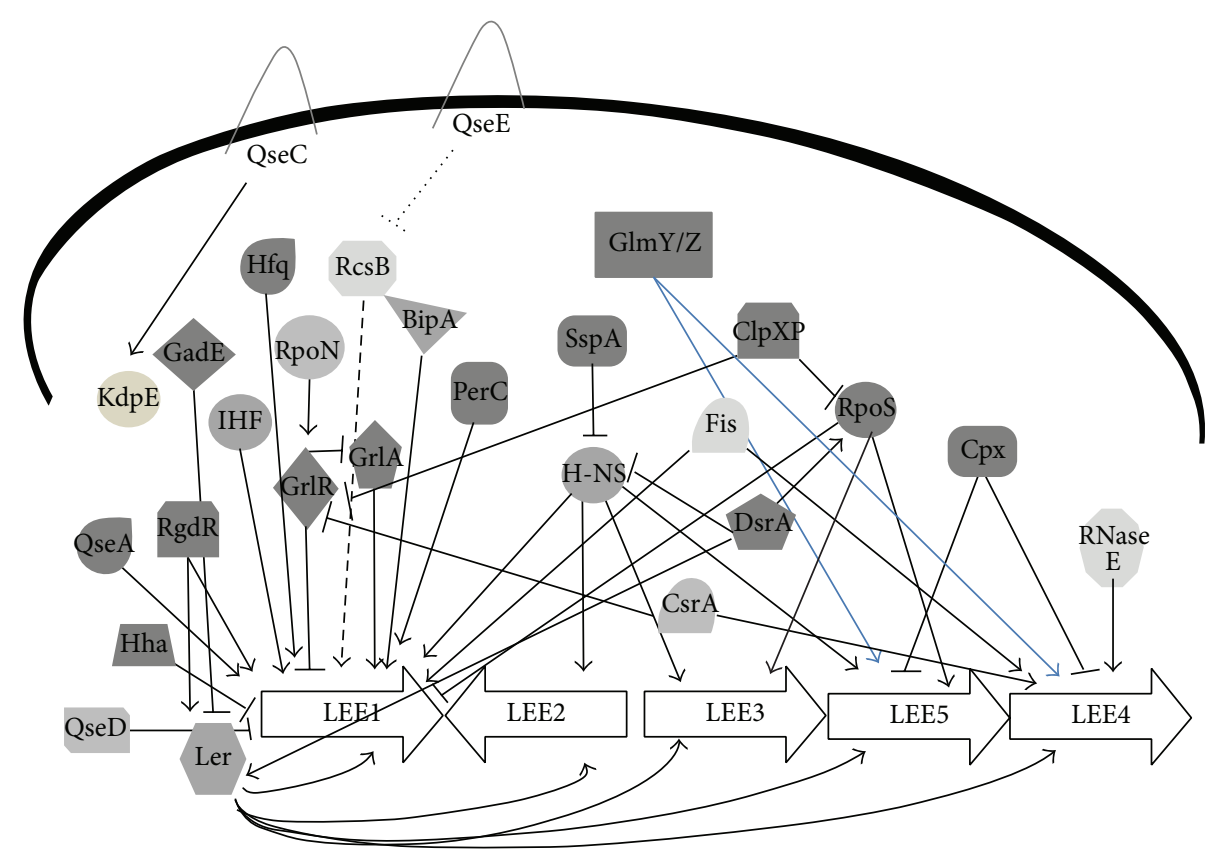

FIGURE 1: Schematic representation of LEE genes transcription regulation. The pointed arrows indicate activation, and repression is represented by blunt arrows.

responsible for the transcriptional activation of the flagella regulon in response to QS. Early studies indicated that an isogenic mutant in the $q s e C$ sensor kinase was unable to respond to AI-3 or epinephrine given exogenously [78]. There are other genes recently described in this signaling cascade, and it is important to notice the identification of $q s e E$ and qseF (encoding a second two-component system), which are involved in regulating $\mathrm{AE}$ [81]. Additionally, QseE has also been shown to sense epinephrine, sulphate, and phosphate, but not AI-3 [82]. The AI-3-dependent QS signaling cascade is present in all Enterobacteriaceae (E. coli, Salmonella spp., Shigella spp., and Yersinia spp.). The most striking feature is that the genes encoding the transcriptional factors of this cascade are always in the exact same context in the chromosome of all these strains and share high levels of identity among these different species, suggesting that this signaling cascade is functionally conserved in Enterobacteriaceae.

\section{Concluding Remarks}

Elucidation of the kinetics of AE lesion formation demonstrated that this complex phenotype is tightly regulated in response to environmental signals, and there are several molecules and mechanisms involved in this regulation. It is important to notice that there are a lot of molecules and environmental signals involved in this pathogenicity island regulation, and this very complex cascade of regulators helps to activate or repress virulence, sensing the conditions of the environment and pointing to the colonization process. We must understand these mechanisms and these regulators because these molecules can be targets to block the virulence factors transcription and translation, consecutively preventing the colonization. We demonstrate the complex signaling cascade on a scheme (Figure 1).

\section{Conflict of Interests}

The authors declare that there is no conflict of interests regarding the publication of this paper.

\section{References}

[1] M. A. Croxen and B. B. Finlay, "Molecular mechanisms of Escherichia coli pathogenicity," Nature Reviews Microbiology, vol. 8, no. 1, pp. 26-38, 2010.

[2] H. W. Moon, S. C. Whipp, R. A. Argenzio, M. M. Levine, and R. A. Giannella, "Attaching and effacing activities of rabbit and human enteropathogenic Escherichia coli in pig and rabbit intestines," Infection and Immunity, vol. 41, no. 3, pp. 1340-1351, 1983.

[3] J. E. Afset, L. Bevanger, P. Romundstad, and K. Bergh, "Association of atypical enteropathogenic Escherichia coli (EPEC) with prolonged diarrhoea," Journal of Medical Microbiology, vol. 53, no. 11, pp. 1137-1144, 2004.

[4] V. Bueris, M. P. Sircili, C. R. Taddei et al., "Detection of diarrheagenic Escherichia coli from children with and without diarrhea in Salvador, Bahia, Brazil," Memorias do Instituto Oswaldo Cruz, vol. 102, no. 7, pp. 839-844, 2007.

[5] T. Estrada-Garcia, C. Lopez-Saucedo, R. Thompson-Bonilla et al., "Association of diarrheagenic escherichia coli pathotypes with infection and diarrhea among mexican children and association of atypical enteropathogenic E. coli with acute diarrhea," Journal of Clinical Microbiology, vol. 47, no. 1, pp. 9398, 2009. 
[6] J. B. Kaper, J. P. Nataro, and H. L. T. Mobley, "Pathogenic Escherichia coli," Nature Reviews Microbiology, vol. 2, no. 2, pp. 123-140, 2004.

[7] B. Kenny, R. DeVinney, M. Stein, D. J. Reinscheid, E. A. Frey, and B. B. Finlay, "Enteropathogenic E. coli (EPEC) transfers its receptor for intimate adherence into mammalian cells," Cell, vol. 91, no. 4, pp. 511-520, 1997.

[8] A. E. Jerse, J. Yu, B. D. Tall, and J. B. Kaper, "A genetic locus of enteropathogenic Escherichia coli necessary for the production of attaching and effacing lesions on tissue culture cells," Proceedings of the National Academy of Sciences of the United States of America, vol. 87, no. 20, pp. 7839-7843, 1990.

[9] S. Knutton, T. Baldwin, P. H. Williams, and A. S. McNeish, "Actin accumulation at sites of bacterial adhesion to tissue culture cells: basis of a new diagnostic test for enteropathogenic and enterohemorrhagic Escherichia coli," Infection and Immunity, vol. 57, no. 4, pp. 1290-1298, 1989.

[10] T. K. Mcdaniel, K. G. Jarvis, M. S. Donnenberg, and J. B. Kaper, "A genetic locus of enterocyte effacement conserved among diverse enterobacterial pathogens," Proceedings of the National Academy of Sciences of the United States of America, vol. 92, no. 5, pp. 1664-1668, 1995.

[11] J. L. Mellies, S. J. Elliott, V. Sperandio, M. S. Donnenberg, and J. B. Kaper, "The Per regulon of enteropathogenic Escherichia coli: identification of a regulatory cascade and a novel transcriptional activator, the locus of enterocyte effacement (LEE)-encoded regulator (Ler)," Molecular Microbiology, vol. 33, no. 2, pp. 296306, 1999.

[12] K. G. Jarvis, J. A. Girón, A. E. Jerse, T. K. Mcdaniel, M. S. Donnenberg, and J. B. Kaper, "Enteropathogenic Escherichia coli contains a putative type III secretion system necessary for the export of proteins involved in attaching and effacing lesion formation," Proceedings of the National Academy of Sciences of the United States of America, vol. 92, no. 17, pp. 7996-8000, 1995.

[13] S. J. Elliott, V. Sperandio, J. A. Giron et al., "The locus of enterocyte effacement (LEE)-encoded regulator controls expression of both LEE- and non-LEE-encoded virulence factors in enteropathogenic and enterohemorrhagic Escherichia coli," Infection and Immunity, vol. 68, no. 11, pp. 6115-6126, 2000.

[14] J. Garmendia, G. Frankel, and V. F. Crepin, "Enteropathogenic and enterohemorrhagic Escherichia coli infections: translocation, translocation, translocation," Infection and Immunity, vol. 73, no. 5, pp. 2573-2585, 2005.

[15] M. S. Donnenberg, J. Yu, and J. B. Kaper, "A second chromosomal gene necessary for intimate attachment of enteropathogenic Escherichia coli to epithelial cells," Journal of Bacteriology, vol. 175, no. 15, pp. 4670-4680, 1993.

[16] T. J. Ochoa and C. A. Contreras, "Enteropathogenic Escherichia coli infection in children," Current Opinion in Infectious Diseases, vol. 24, no. 5, pp. 478-483, 2011.

[17] R. T. Hernandes, W. P. Elias, M. A. M. Vieira, and T. A. T. Gomes, "An overview of atypical enteropathogenic Escherichia coli," FEMS Microbiology Letters, vol. 297, no. 2, pp. 137-149, 2009.

[18] T. J. Ochoa, F. Barletta, C. Contreras, and E. Mercado, "New insights into the epidemiology of enteropathogenic Escherichia coli infection," Transactions of the Royal Society of Tropical Medicine and Hygiene, vol. 102, no. 9, pp. 852-856, 2008.

[19] R. M. Robins-Browne, "Traditional enteropathogenic Escherichia coli of infantile diarrhea," Reviews of Infectious Diseases, vol. 9, no. 1, pp. 28-53, 1987.
[20] L. R. Trabulsi, A. Manissadjan, H. A. Penna, R. Liberatore, L. Duailibe, and E. S. Peixoto, "Infantile diarrhea caused by enteropathogenic colibacilli. Preliminary studies on the occurrence of certain groups and serological types in Sao Paulo," Revista do Instituto de Medicina Tropical de São Paulo, vol. 3, pp. 267-270, 1961.

[21] M. R. Toledo, M. D. O. C. Alvariza, J. Murahovsch, S. R. Ramos, and L. R. Trabulsi, "Enteropathogenic Escherichia coli serotypes and endemic diarrhea in infants," Infection and Immunity, vol. 39, pp. 586-589, 1983.

[22] T. A. T. Gomes, V. Rassi, K. L. MacDonald et al., "Enteropathogens associated with acute diarrheal disease in urban infants in Sao Paulo, Brazil," Journal of Infectious Diseases, vol. 164, no. 2, pp. 331-337, 1991.

[23] L. R. Trabulsi, R. Keller, and T. A. Tardelli Gomes, "Typical and atypical enteropathogenic Escherichia coli," Emerging Infectious Diseases, vol. 8, no. 5, pp. 508-513, 2002.

[24] J. P. Nataro and J. B. Kaper, "Diarrheagenic Escherichia coli," Clinical Microbiology Reviews, vol. 11, no. 1, pp. 142-201, 1998.

[25] J. B. Kaper and A. D. O'Brien, Escherichia coli O157:H7 and Other Shiga Toxin-Producing E. coli Strains, American Society for Microbiology, Washington, DC, USA, 1998.

[26] D. Friedberg, T. Umanski, Y. Fang, and M. Rosenshine, "Hierarchy in the expression of the locus of enterocyte effacement genes of enteropathogenic Escherichia coli," Molecular Microbiology, vol. 34, no. 5, pp. 941-952, 1999.

[27] V. Sperandio, J. L. Mellies, R. M. Delahay et al., "Activation of enteropathogenic Escherichia coli (EPEC) LEE2 and LEE3 operons by Ler," Molecular Microbiology, vol. 38, no. 4, pp. 781793, 2000.

[28] V. H. Bustamante, F. J. Santana, E. Calva, and J. L. Puente, "Transcriptional regulation of type III secretion genes in enteropathogenic Escherichia coli: ler antagonizes H-NSdependent repression," Molecular Microbiology, vol. 39, no. 3, pp. 664-678, 2001.

[29] J. L. Mellies, A. M. S. Barron, and A. M. Carmona, "Enteropathogenic and enterohemorrhagic Escherichia coli virulence gene regulation," Infection and Immunity, vol. 75, no. 9, pp. 4199-4210, 2007.

[30] W. Deng, J. L. Puente, S. Gruenheid et al., "Dissecting virulence: Systematic and functional analyses of a pathogenicity island," Proceedings of the National Academy of Sciences of the United States of America, vol. 101, no. 10, pp. 3597-3602, 2004.

[31] J. Barba, V. H. Bustamante, M. A. Flores-Valdez, W. Deng, B. B. Finlay, and J. L. Puente, "A positive regulatory loop controls expression of the locus of enterocyte effacementencoded regulators Ler and GrlA," Journal of Bacteriology, vol. 187, no. 23, pp. 7918-7930, 2005.

[32] E. A. Creasey, R. M. Delahay, S. J. Daniell, and G. Frankel, "Yeast two-hybrid system survey of interactions between LEEencoded proteins of enteropathogenic Escherichia coli," Microbiology, vol. 149, no. 8, pp. 2093-2106, 2003.

[33] L.-H. Huang and W.-J. Syu, "GrlA of enterohemorrhagic Escherichia coli O157:H7 activates LEE1 by binding to the promoter region," Journal of Microbiology, Immunology and Infection, vol. 41, no. 1, pp. 9-16, 2008.

[34] C. Lara, A. Huerta-Saquero, R. Jimenez-Mejía, and J. L. PuenteGarcía, "The repressor activity of GrlR, a LEE-encoded negative regulator of enteropathogenic Escherichia coli, is antagonized by GrlA through protein-protein interactions," in Proceedings 
of the 109th General Meeting of the American Society for Microbiology, abstr. B-197, p. 71, American Society for Microbiology, Washington, DC, USA, 2009.

[35] O. G. Gomez-Duarte and J. B. Kaper, "A plasmid-encoded regulatory region activates chromosomal eaeA expression in enteropathogenic Escherichia coli," Infection and Immunity, vol. 63, no. 5, pp. 1767-1776, 1995.

[36] V. H. Bustamante, M. I. Villalba, V. A. García-Angulo et al., "PerC and GrlA independently regulate Ler expression in enteropathogenic Escherichia coli," Molecular Microbiology, vol. 82, no. 2, pp. 398-415, 2011.

[37] S. Iyoda and H. Watanabe, "ClpXP protease controls expression of the type III protein secretion system through regulation of RpoS and GrlR levels in enterohemorrhagic Escherichia coli," Journal of Bacteriology, vol. 187, no. 12, pp. 4086-4094, 2005.

[38] M. E. Porter, P. Mitchell, A. Free, D. G. E. Smith, and D. L. Gally, "The LEE1 promoters from both enteropathogenic and enterohemorrhagic Escherichia coli can be activated by PerClike proteins from either organism," Journal of Bacteriology, vol. 187, no. 2, pp. 458-472, 2005.

[39] K. R. Haack, C. L. Robinson, K. J. Miller, J. W. Fowlkes, and J. L. Mellies, "Interaction of Ler at the LEE5 (tir) operon of enteropathogenic Escherichia coli," Infection and Immunity, vol. 71, no. 1, pp. 384-392, 2003.

[40] K. Forsman, B. Sondén, M. Göransson, and B. E. Uhlin, "Antirepression function in Escherichia coli for the cAMPcAMP receptor protein transcriptional activator," Proceedings of the National Academy of Sciences of the United States of America, vol. 89, no. 20, pp. 9880-9884, 1992.

[41] B. J. A. M. Jordi, B. Dagberg, L. A. M. De Haan et al., "The positive regulator $\mathrm{CfaD}$ overcomes the repression mediated by histone-like protein H-NS (H1) in the CFA/I fimbrial operon of Escherichia coli," The EMBO Journal, vol. 11, no. 7, pp. 2627-2632, 1992.

[42] T. Tobe, M. Yoshikawa, T. Mizuno, and C. Sasakawa, "Transcriptional control of the invasion regulatory gene virB of Shigella flexneri: activation by VirF and repression by H-NS," Journal of Bacteriology, vol. 175, no. 19, pp. 6142-6149, 1993.

[43] T. Umanski, I. Rosenshine, and D. Friedberg, "Thermoregulated expression of virulence genes in enteropathogenic Escherichia coli," Microbiology, vol. 148, no. 9, pp. 2735-2744, 2002.

[44] S. Iyoda and H. Watanabe, "Positive effects of multiple pch genes on expression of the locus of enterocyte effacement genes and adherence of enterohaemorrhagic Escherichia coli O157:H7 to HEp-2 cells," Microbiology, vol. 150, no. 7, pp. 2357-2371, 2004.

[45] M. D. Goldberg, M. Johnson, J. C. D. Hinton, and P. H. Williams, "Role of the nucleoid-associated protein fis in the regulation of virulence properties of enteropathogenic Escherichia coli," Molecular Microbiology, vol. 41, no. 3, pp. 549-559, 2001.

[46] A. J. Grant, M. Farris, P. Alefounder, P. H. Williams, M. J. Woodward, and C. D. O'Connor, "Co-ordination of pathogenicity island expression by the BipA GTPase in enteropathogenic Escherichia coli (EPEC)," Molecular Microbiology, vol. 48, no. 2, pp. 507-521, 2003.

[47] A. F. Flockhart, J. J. Tree, X. Xu et al., "Identification of a novel prophage regulator in Escherichia coli controlling the expression of type III secretion," Molecular Microbiology, vol. 83, no. 1, pp. 208-223, 2012.

[48] V. K. Sharma and R. L. Zuerner, "Role of hha and ler in transcriptional regulation of the esp operon of enterohemorrhagic Escherichia coli O157:H7," Journal of Bacteriology, vol. 186, no. 21, pp. 7290-7301, 2004.
[49] J. T. Riordan, J. A. Tietjen, C. W. Walsh, J. E. Gustafson, and T. S. Whittam, "Inactivation of alternative sigma factor $54(\mathrm{RpoN})$ leads to increased acid resistance, and alters locus of enterocyte effacement (LEE) expression in Escherichia coli O157:H7," Microbiology, vol. 156, no. 3, pp. 719-730, 2010.

[50] S. K. Vanaja, T. M. Bergholz, and T. S. Whittam, "Characterization of the Escherichia coli O157:H7 Sakai GadE regulon," Journal of Bacteriology, vol. 191, no. 6, pp. 1868-1877, 2009.

[51] D. M. Macritchie, J. D. Ward, A. Z. Nevesinjac, and T. L. Raivio, "Activation of the Cpx envelope stress response downregulates expression of several locus of enterocyte effacementencoded genes in enteropathogenic Escherichia coli," Infection and Immunity, vol. 76, no. 4, pp. 1465-1475, 2008.

[52] D. M. MacRitchie, N. Acosta, and T. L. Raivio, "DegP is involved in Cpx-mediated posttranscriptional regulation of the type III secretion apparatus in enteropathogenic Escherichia coli," Infection and Immunity, vol. 80, no. 5, pp. 1766-1772, 2012.

[53] P. B. Lodato and J. B. Kaper, "Post-transcriptional processing of the LEE4 operon in enterohaemorrhagic Escherichia coli," Molecular Microbiology, vol. 71, no. 2, pp. 273-290, 2009.

[54] P. Babitzke and T. Romeo, "CsrB sRNA family: sequestration of RNA-binding regulatory proteins," Current Opinion in Microbiology, vol. 10, no. 2, pp. 156-163, 2007.

[55] S. Bhatt, A. N. Edwards, H. T. T. Nguyen, D. Merlin, T. Romeo, and D. Kalman, "The RNA binding protein CsrA is a pleiotropic regulator of the locus of enterocyte effacement pathogenicity island of enteropathogenic Escherichia coli," Infection and Immunity, vol. 77, no. 9, pp. 3552-3568, 2009.

[56] T. Tomoyasu, A. Takaya, Y. Handa, K. Karata, and T. Yamamoto, "ClpXP controls the expression of LEE genes in enterohaemorrhagic Escherichia coli," FEMS Microbiology Letters, vol. 253, no. 1, pp. 59-66, 2005.

[57] V. Sperandio, J. L. Mellies, W. Nguyen, S. Shin, and J. B. Kaper, "Quorum sensing controls expression of the type III secretion gene transcription and protein secretion in enterohemorrhagic and enteropathogenic Escherichia coli," Proceedings of the National Academy of Sciences of the United States of America, vol. 96, no. 26, pp. 15196-15201, 1999.

[58] M.-H. Laaberki, N. Janabi, E. Oswald, and F. Repoila, “Concert of regulators to switch on LEE expression in enterohemorrhagic Escherichia coli O157:H7: interplay between Ler, GrlA, HNS and RpoS," International Journal of Medical Microbiology, vol. 296, no. 4-5, pp. 197-210, 2006.

[59] S. Gottesman, "The small RNA regulators of Escherichia coli: roles and mechanisms," Annual Review of Microbiology, vol. 58, pp. 303-328, 2004.

[60] R. A. Lease, M. E. Cusick, and M. Belfort, "Riboregulation in Escherichia coli: DsrA RNA acts by RNA:RNA interactions at multiple loci," Proceedings of the National Academy of Sciences of the United States of America, vol. 95, no. 21, pp. 12456-12461, 1998.

[61] N. Majoalani, C. Cunning, D. Sledjeski, T. Elliott, and S. Gottesman, "DsrA RNA regulates translation of RpoS message by an anti-antisense mechanism, independent of its action as an antisilencer of transcription," Proceedings of the National Academy of Sciences of the United States of America, vol. 95, no. 21, pp. 12462-12467, 1998.

[62] P. Valentin-Hansen, M. Eriksen, and C. Udesen, "The bacterial Sm-like protein Hfq: a key player in RNA transactions," Molecular Microbiology, vol. 51, no. 6, pp. 1525-1533, 2004.

[63] E. A. Shakhnovich, B. M. Davis, and M. K. Waldor, "Hfq negatively regulates type III secretion in EHEC and several 
other pathogens," Molecular Microbiology, vol. 74, no. 2, pp. 347$363,2009$.

[64] A.-M. Hansen and J. B. Kaper, "Hfq affects the expression of the LEE pathogenicity island in enterohaemorrhagic Escherichia coli," Molecular Microbiology, vol. 73, no. 3, pp. 446-465, 2009.

[65] M. M. Kendall, C. C. Gruber, D. A. Rasko, D. T. Hughes, and V. Sperandio, "Hfq virulence regulation in enterohemorrhagic Escherichia coli O157:H7 Strain 86-24," Journal of Bacteriology, vol. 193, no. 24, pp. 6843-6851, 2011.

[66] C. C. Gruber and V. Sperandio, "Posttranscriptional control of microbe-induced rearrangement of host cell actin," mBio, vol. 5, no. 1, Article ID e01025-13, 2014.

[67] M. M. Takao, H. Yen, and T. Tobe, "LeuO enhances butyrateinduced virulence expression through a positive regulatory loop in enterohaemorrhagic Escherichia coli," Molecular Microbiology, vol. 93, no. 6, pp. 1302-1313, 2014.

[68] A. R. Pacheco, M. M. Curtis, J. M. Ritchie et al., "Fucose sensing regulates bacterial intestinal colonization," Nature, vol. 491, no. 7427, pp. 113-117, 2012.

[69] M. M. Kendall, C. C. Gruber, C. T. Parker, and V. Sperandio, "Ethanolamine controls expression of genes encoding components involved in interkingdom signaling and virulence in enterohemorrhagic Escherichia coli O157:H7," mBio, vol. 3, no. 3, Article ID e00050-12, 2012.

[70] J. W. Njoroge, C. Gruber, and V. Sperandio, “The interacting Cra and $\mathrm{KdpE}$ regulators are involved in the expression of multiple virulence factors in enterohemorrhagic Escherichia coli," Journal of Bacteriology, vol. 195, no. 11, pp. 2499-2508, 2013.

[71] M. P. Sircili, M. Walters, L. R. Trabulsi, and V. Sperandio, "Modulation of enteropathogenic Escherichia coli virulence by quorum sensing," Infection and Immunity, vol. 72, no. 4, pp. 2329-2337, 2004.

[72] B. Michael, J. N. Smith, S. Swift, F. Heffron, and B. M. M. Ahmer, "SdiA of Salmonella enterica is a LuxR homolog that detects mixed microbial communities," Journal of Bacteriology, vol. 183, no. 19, pp. 5733-5742, 2001.

[73] J. Lee, A. Jayaraman, and T. K. Wood, "Indole is an inter-species biofilm signal mediated by SdiA," BMC Microbiology, vol. 7, article 42, 2007.

[74] H. Sheng, Y. N. Nguyen, C. J. Hovde, and V. Sperandio, "SdiA aids enterohemorrhagic Escherichia coli carriage by cattle fed a forage or grain diet," Infection and Immunity, vol. 81, no. 9, pp. 3472-3478, 2013.

[75] B. Bommarius, A. Anyanful, Y. Izrayelit et al., "A family of indoles regulate virulence and shiga toxin production in pathogenic E. coli," PLoS ONE, vol. 8, no. 1, Article ID e54456, 2013.

[76] V. Sperandio, A. G. Torres, B. Jarvis, J. P. Nataro, and J. B. Kaper, "Bacteria-host communication: the language of hormones," Proceedings of the National Academy of Sciences of the United States of America, vol. 100, no. 15, pp. 8951-8956, 2003.

[77] M. Walters, M. P. Sircili, and V. Sperandio, "AI-3 synthesis is not dependent on luxS in Escherichia coli," Journal of Bacteriology, vol. 188, no. 16, pp. 5668-5681, 2006.

[78] M. B. Clarke, D. T. Hughes, C. Zhu, E. C. Boedeker, and V. Sperandio, "The QseC sensor kinase: a bacterial adrenergic receptor," Proceedings of the National Academy of Sciences of the United States of America, vol. 103, no. 27, pp. 10420-10425, 2006.

[79] D. A. Rasko, C. G. Moreira, R. L. De et al., "Targeting QseC signaling and virulence for antibiotic development," Science, vol. 321, no. 5892, pp. 1078-1080, 2008.
[80] V. Sperandio, C. C. Li, and J. B. Kaper, "Quorum-sensing Escherichia coli regulator A: a regulator of the LysR family involved in the regulation of the locus of enterocyte effacement pathogenicity island in enterohemorrhagic E. coli," Infection and Immunity, vol. 70, no. 6, pp. 3085-3093, 2002.

[81] N. C. Reading, A. G. Torres, M. M. Kendall, D. T. Hughes, K. Yamamoto, and V. Sperandio, "A novel two-component signaling system that activates transcription of an enterohemorrhagic Escherichia coli effector involved in remodeling of host actin," Journal of Bacteriology, vol. 189, no. 6, pp. 2468-2476, 2007.

[82] N. C. Reading, D. A. Rasko, A. G. Torres, and V. Sperandio, "The two-component system QseEF and the membrane protein QseG link adrenergic and stress sensing to bacterial pathogenesis," Proceedings of the National Academy of Sciences of the United States of America, vol. 106, no. 14, pp. 5889-5894, 2009.

[83] B. J. Habdas, J. Smart, J. B. Kaper, and V. Sperandio, “The LysRtype transcriptional regulator QseD alters type three secretion in enterohemorrhagic Escherichia coli and motility in K-12 Escherichia coli," Journal of Bacteriology, vol. 192, no. 14, pp. 3699-3712, 2010. 

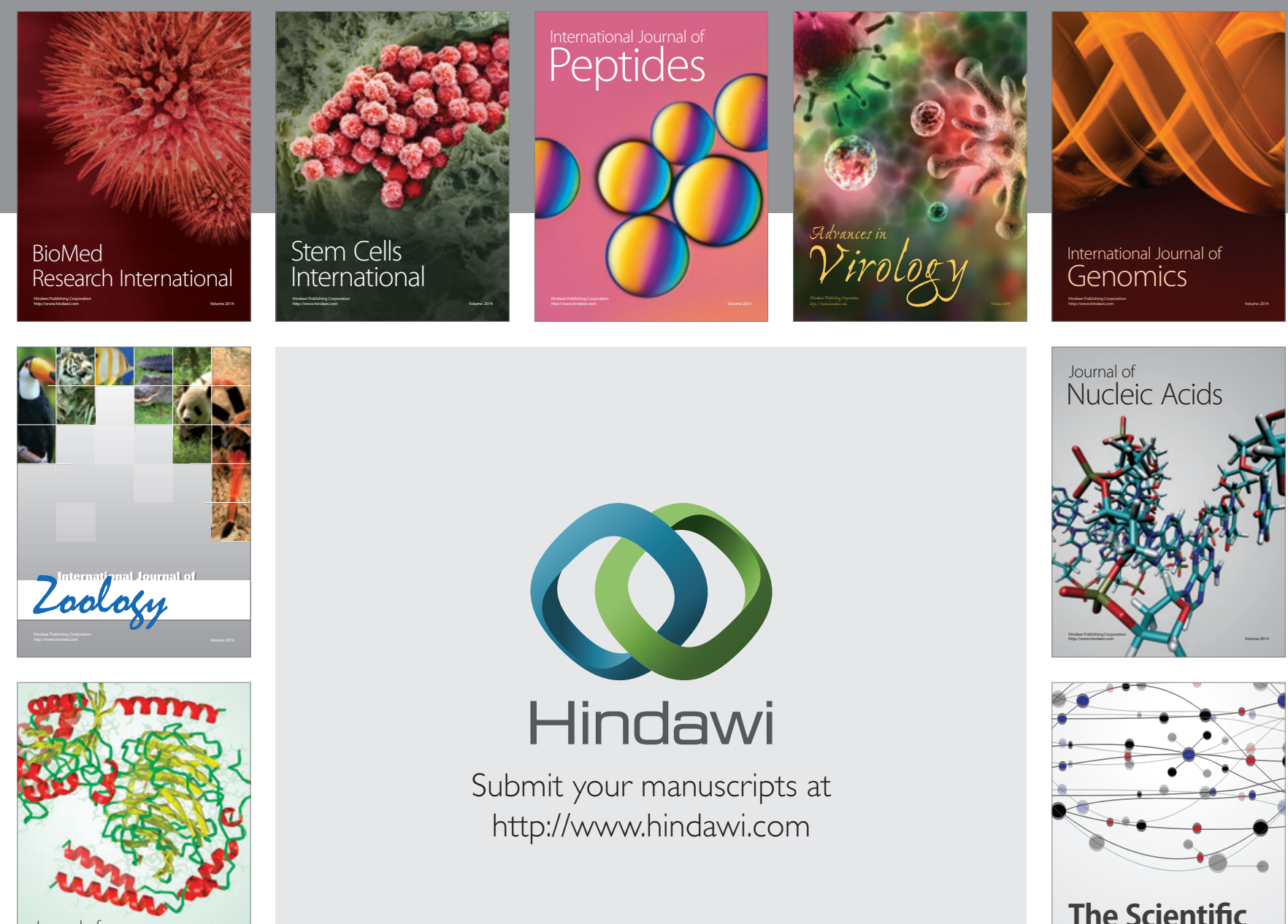

Submit your manuscripts at

http://www.hindawi.com

Journal of
Signal Transduction
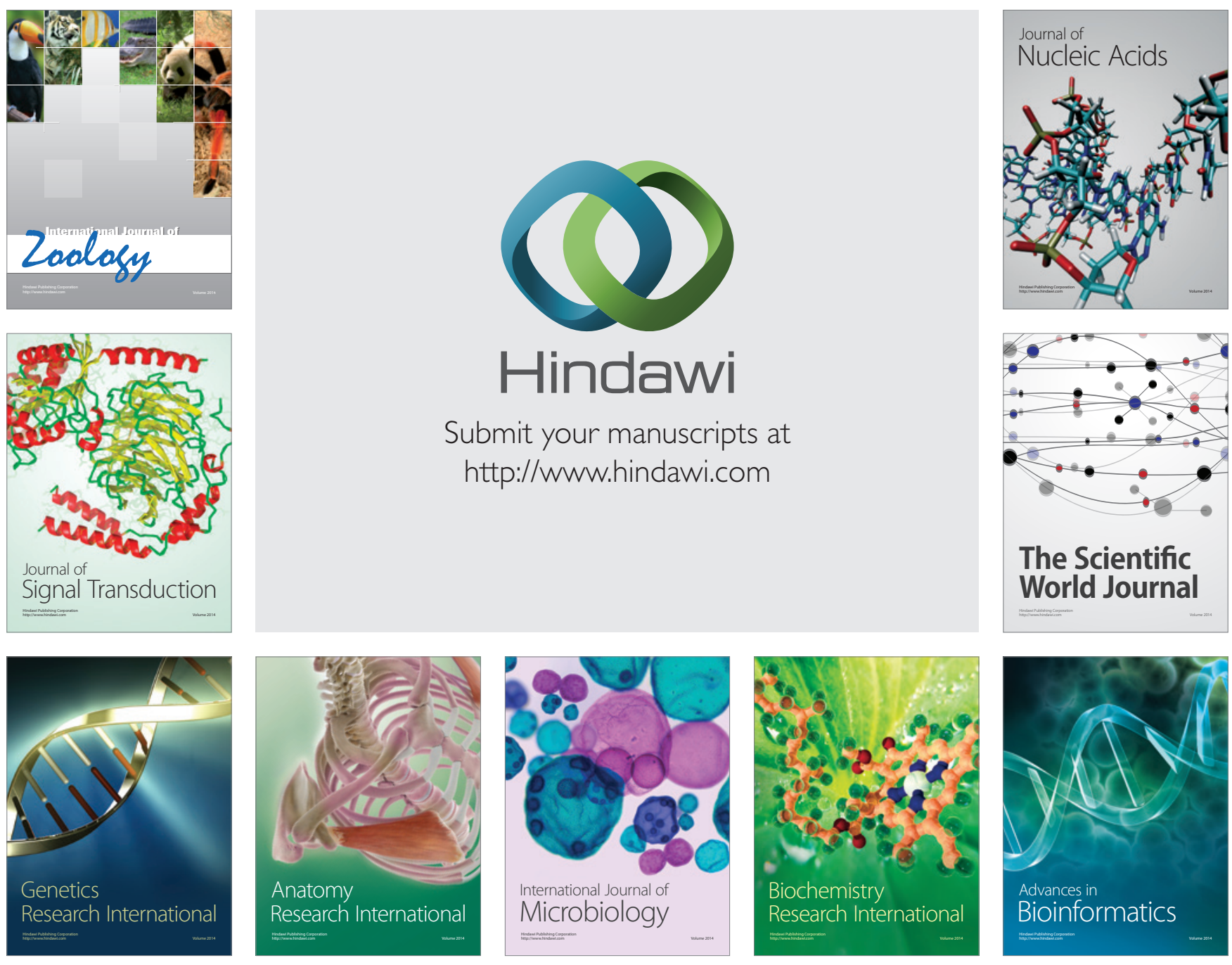

The Scientific World Journal
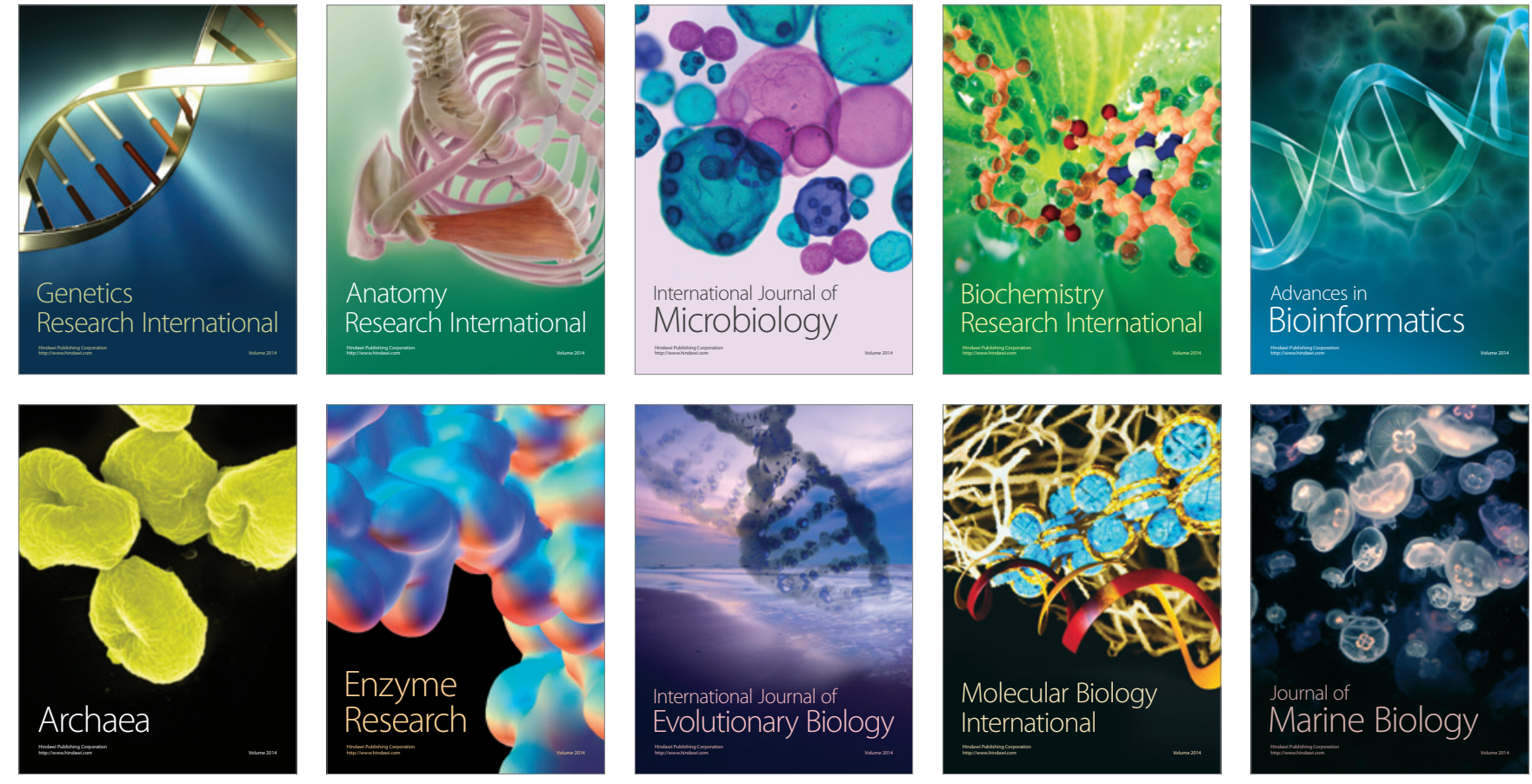